\title{
INFLUENCE OF DIFFERENT SHAPES OF GEOMETRIC IMPERFECTIONS ON THE STRUCTURAL BEHAVIOR OF BEAMS WITH LARGE WEB OPENINGS
}

\author{
Teixeira F. B. *, Caldas R. B. and Grilo L. F. \\ Federal University of Minas Gerais, Belo Horizonte, Brazil \\ * (Corresponding author: E-mail: felipebarbosateixeira@gmail.com)
}

\section{A B S T RA C T}

This paper explores the influence of four different shapes of geometric imperfection upon the collapse of castellated and cellular beams. A numerical model developed in ANSYS and calibrated against experimental results was used to investigate the effects of each imperfection shape. The global imperfection (weak-axis bending) did not affect web-post stability. Webpost bending favored the development of plastic yielding, while web-post misalignment and the local buckling mode strongly compromised web-post stability. The choice of imperfection shape was shown to determine the failure mode of the beams, directly affecting the quality of the numerical results and potentially influencing design decisions.

\begin{tabular}{ll} 
A R T I C L E & H I S T O R Y \\
\hline Received: & 8 October 2019 \\
$\begin{array}{l}\text { Revised: } \\
\text { Accepted: }\end{array}$ & 2 June 2020 June 2020
\end{tabular}

\section{K E Y W O R D S}

large web opening; geometric imperfection; numerical analysis; web-post buckling; lateral-torsional buckling

\section{Introduction}

Castellated and cellular beams are structural elements with large web openings, usually built from a plain-webbed I section. The web of the parent section is cut longitudinally (following a pattern that defines the shape of the openings), the upper and lower halves are moved with respect to each other, and both segments are joined again by welding at the web-post (Fig. 1).
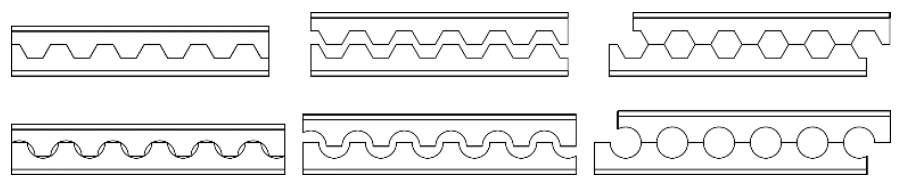

Fig. 1 Conventional process for building castellated beams

Castellated and cellular beams under bending and shear force might display the following failure modes:

- $\quad$ lateral-torsional buckling (LTB, Fig. 2-a) [1,2,3,4];

- $\quad$ plastic hinge, which might occur due to the Vierendeel mechanism (VM, Fig. 2-d) or due to pure bending (PH) [5,6,7];

- $\quad$ longitudinal shear at the web-post (LS, Fig. 2-e) [5];

- $\quad$ web-post buckling due to shear (WBS, Fig. 2-b) [8,9];

- web-post buckling due to compression (WBC, Fig. 2-c) [1,5,10];

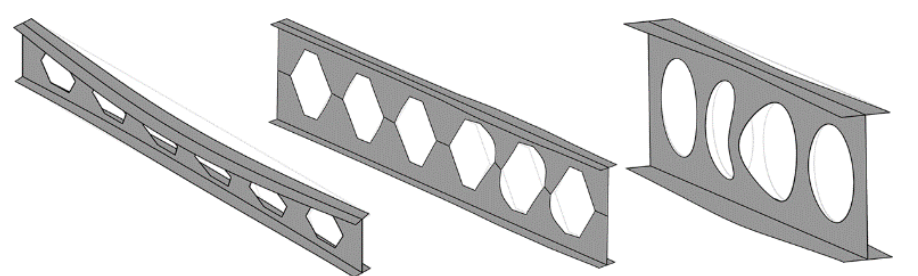

(a)

(b)

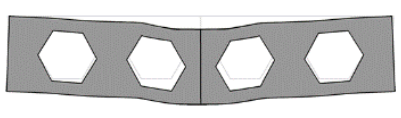

(d)

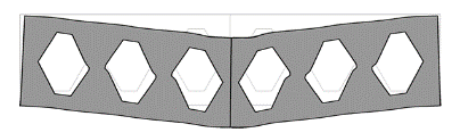

(e)

Fig. 2 Common types of collapse for castellated and cellular beams

Castellated and cellular beams can also be subjected to more improbable failure modes, such as plastic yielding of the web-post due to bending, vertical shearing of the T sections, or the local buckling at the flanges, none of which will be studied in this paper.
The structural behavior of beams with large web openings can be simulated by employing numerical models capable of performing finite element analysis. Such numerical models must be able to accurately predict the mode of failure given the loads, boundary conditions, geometry, and material models. For the study of structural instability in a non-linear analysis the numerical model must be provided with imperfections that are capable of triggering the instability. The standard procedure consists of first performing an eigenvalue analysis to obtain the buckling modes of the beam and then importing the mode shape (eigenvector) associated with the lowest buckling load (eigenvalue). The imported geometry is then used to perform a non-linear analysis $[8,9]$.

The consequences of the shape and magnitude of the geometric imperfection upon the failure mode have been investigated for structures known to be sensitive to instability such as domes [11,12], but not yet for the webs of beams with large web openings. Masri \& Lui [13] showed how the magnitude of the geometric imperfection is directly linked to the flexural resistance of steel delta girders (plain-webbed I beams with inclined plates connecting the compressed flange to the web) to lateral-torsional buckling.

The use of the eigenmode characterized as lateral distortional buckling was adopted by Ellobody [14,15] to successfully study structural failure due to the interaction of combined buckling modes in castellated and cellular beams.

However, the actual initial geometry of the beam is largely a result of the fabrication process, and might not display the shape of the buckling mode [2]. In fact, Nseir et al. [4] and Vieira [8] have measured castellated and cellular beams and shown that the geometric imperfections do not conform to the mode shapes resulting from an eigenvalue analysis. For thin-walled sections Gehring \& Saal [16] have shown how accounting for the actual imperfections that result from the production process affect both the ultimate loads and the shape of the failure mode.

Furthermore, when analyzing beams that, because of their geometry or boundary conditions, lie outside narrow ranges of slenderness, the first buckling mode shape ceases to be the expected one (i.e., web-post buckling due to shear for sturdy beams, and lateral-torsional buckling for slender ones). It is possible to search higher modes for the desired shape, but these usually display a mixture of many local buckling effects, and introducing such an unpredictable shape might compromise the quality of the numerical simulation.

In this paper a novel approach to the introduction of geometric imperfections was studied. The shapes of the geometric imperfections introduced were chosen based on experimental measurements (performed by Vieira [8], Nseir et al. [4], and Sonck [2]) and on factory recommendations by ArcelorMittal [17], a company that manufactures beams with large web openings of both conventional and novel shapes. This approach contrasts with the conventional one, according to which the shape of the imperfection is always the buckling mode and only the magnitude of the imperfection is informed by experimental measurement [8].

\section{Shapes of the geometric imperfections}


The most significant geometric imperfections observed in castellated and cellular beams are:

- global bending of the longitudinal axis of the beam about the weak-axis of inertia (Fig. 3-a);

- $\quad$ bending of the web (Fig. 3-b);

- misalignment between the upper and lower halves of the beam at the welded section (Fig. 3-c).

The shape of the buckling mode (web-post buckling due to shear, Fig. 2-b) was included in this study for the sake of comparison, given that it is adopted in the conventional approach.

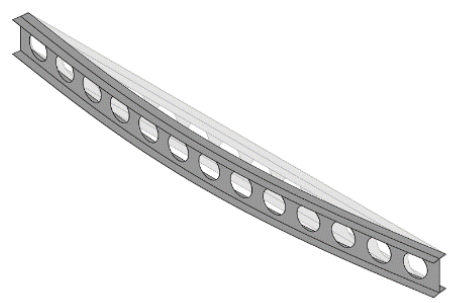

(a)

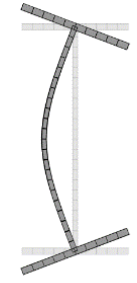

(b)

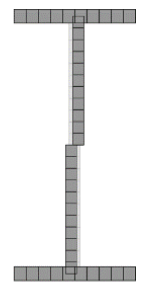

(c)
Fig. 3 Imperfections: a) weak-axis bending; b) web bending; c) web-post misalignment

The weak-axis bending and the web bending shapes were obtained by performing a linear elastic analysis in which a uniformly distributed load was applied (lateral loads at both flanges for the global bending and at mid-depth for the web bending). The buckling modes were obtained by performing an eigenvalue analysis. The web-post misalignment was introduced directly by offsetting the upper and lower halves of the web's cross section in opposite directions.

\section{Finite element modeling and validation}

The finite element package ANSYS 14.0 [18] was used to perform the numerical simulations presented in this paper. In order to study a large quantity of beams, a parametric model, capable of generating any geometry of castellated and cellular beam, was developed using ANSYS's native programming language named APDL (Ansys Parametric Design Language).

\subsection{Experimental result database}

The geometric imperfection numerical study was performed using beams that were subjected to actual physical experiments. Such experiments were collected from the available literature on castellated and cellular beams and were carefully selected in order to include beams that fail globally $[2,4,6]$ and beams that fail locally $[1,6,8,9,19]$. The data collected add up to 42 experiments, each one identified in Table 1 and Table 2, in which: $L$ is the length of the beam; $d_{g}$ is the section depth; $d_{0}$ is the opening height; $b_{f}$ is the flange width; $s_{w}$ is the webpost width; $s_{0}$ is the opening width; $t_{f}$ is the flange thickness; and $t_{w}$ is the web thickness. The experimental setups were either of the three point bending (3P) or four point bending (4P) type, and the load-displacement curves presented throughout this paper follow the template shown in Fig. 4. When displaying results (deformed shapes, strain patterns) the flanges and web-stiffeners of the beams were often omitted, leaving only the web to be shown for greater clarity.
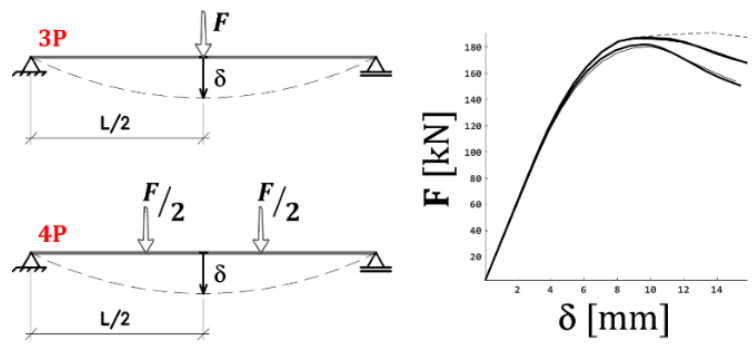

Fig. 4 Diagram of experiments reproduced and load-displacement curve template

Table 1

Castellated beams: geometric data of the experiments compiled (values in $\mathrm{mm}$ )

\begin{tabular}{ccccccccc}
\hline Model & $L$ & $d_{g}$ & $d_{0}$ & $b_{f}$ & $s_{w}$ & $s_{0}$ & $t_{f}$ & $t_{w}$ \\
\hline \multicolumn{8}{c}{ Sonck [2], 4P } \\
CS1_L3 & 3150 & 220 & 118.9 & 83.1 & 73.8 & 136.2 & 7.3 & 5.5 \\
\hline
\end{tabular}

\begin{tabular}{ccccccccc}
\hline CS1_L4 & 3990 & 220 & 118.9 & 83.1 & 73.8 & 136.2 & 7.3 & 5.5 \\
CS1_L6 & 6090 & 220 & 118.9 & 83.1 & 73.8 & 136.2 & 7.3 & 5.5 \\
& & & \multicolumn{7}{c}{ Vieira $[8], 3 \mathrm{P}$} & & & & \\
A1 & 2278 & 452.2 & 301 & 103.7 & 177.2 & 347.3 & 6.1 & 4.9 \\
A2 & 2275 & 450.9 & 298 & 101.8 & 176.5 & 348.3 & 6.1 & 5.1 \\
B1 & 2037 & 453.7 & 301 & 103.5 & 79.9 & 247.2 & 7.1 & 5.7 \\
B2 & 2033 & 451.1 & 302 & 101.4 & 76.8 & 250.6 & 6.1 & 5.1 \\
B3 & 2078 & 458.3 & 307 & 100.7 & 78.6 & 255.0 & 9.1 & 6.6 \\
B4 & 2079 & 462.0 & 310 & 101.7 & 79.8 & 254.2 & 9.3 & 6.4 \\
B5 & 2136 & 472.6 & 316 & 170.5 & 82.7 & 259.5 & 13.1 & 7.8 \\
B6 & 2135 & 472.9 & 317 & 171.3 & 82.3 & 259.9 & 12.5 & 8.0 \\
& & & Veríssimo et al. $[19], 3 \mathrm{P}$ & & & \\
SA1/SA2 & 2251.7 & 450.0 & 300 & 125 & 173.2 & 346.4 & 6.3 & 4.75 \\
SB1/SB2 & 2019.4 & 450.0 & 300 & 125 & 75.4 & 248.6 & 6.3 & 4.75 \\
SB3/SB4 & 2120.4 & 456.5 & 315 & 125 & 79.2 & 261.0 & 8.0 & 6.3 \\
SB5/SB6 & 2187.7 & 487.5 & 325 & 167 & 81.7 & 269.3 & 12.5 & 8.0 \\
SE1/SE2 & 3029.1 & 675.0 & 450 & 150 & 113.1 & 372.9 & 8.0 & 4.75 \\
SX1/SX2 & 3769.5 & 840.0 & 560 & 170 & 140.7 & 464.1 & 8.0 & 4.75 \\
\hline
\end{tabular}

Table 2

Cellular beams: geometric data of the experiments compiled (values in $\mathrm{mm}$ )

\begin{tabular}{|c|c|c|c|c|c|c|c|}
\hline Model & $L$ & $d_{g}$ & $d_{0}$ & $b_{f}$ & $s_{w}$ & $t_{f}$ & $t_{w}$ \\
\hline \multicolumn{8}{|c|}{ Sonck [2], 4P } \\
\hline$C S 2 \_L 3$ & 3150 & 220 & 142.8 & 83.1 & 67.2 & 7.3 & 5.5 \\
\hline$C S 2 \_L 4$ & 3990 & 220 & 142.8 & 83.1 & 67.2 & 7.3 & 5.5 \\
\hline$C S 2 \_L 6$ & 6090 & 220 & 142.8 & 83.1 & 67.2 & 7.3 & 5.5 \\
\hline \multicolumn{8}{|c|}{ Nseir et al. [4], 4P } \\
\hline HEA_340 & 7500 & 472.1 & 345 & 297.7 & 170 & 16.0 & 10.4 \\
\hline$I P E \_330$ & 11000 & 446.5 & 345 & 161.7 & 50 & 10.8 & 7.9 \\
\hline \multicolumn{8}{|c|}{ Tsavdaridis \& D'Mello [9], 3P } \\
\hline$A l T$ & 1700 & 449.8 & 315 & 152.4 & 94.5 & 10.9 & 7.6 \\
\hline$B 1 T$ & 1700 & 449.8 & 315 & 152.4 & 63.0 & 10.9 & 7.6 \\
\hline \multicolumn{8}{|c|}{ Erdal [1], 3P } \\
\hline$E 240 A$ & 2846 & 355.6 & 251 & 106 & 94 & 13.1 & 8.7 \\
\hline$E 240 C$ & 2846 & 355.6 & 251 & 106 & 194 & 13.1 & 8.7 \\
\hline E260 & 2831 & 394.5 & 286 & 113 & 103 & 14.1 & 9.4 \\
\hline$E 280$ & 2820 & 406.9 & 271 & 119 & 163 & 15.2 & 10.1 \\
\hline \multicolumn{8}{|c|}{ Warren [6], 3P (A) and $4 \mathrm{P}(\mathrm{B})$} \\
\hline $1 A$ & 3100 & 289.8 & 200 & 133.4 & 100 & 7.8 & 52.8 \\
\hline$I B$ & 5500 & 289.8 & 200 & 133.4 & 100 & 7.8 & 5.8 \\
\hline $2 A$ & 3800 & 309.3 & 225 & 133.4 & 75 & 7.8 & 5.8 \\
\hline $2 B$ & 5600 & 309.3 & 225 & 133.4 & 75 & 7.8 & 5.8 \\
\hline $3 A$ & 3800 & 435.0 & 300 & 101.6 & 150 & 6.8 & 5.8 \\
\hline $3 B$ & 4200 & 435.0 & 300 & 101.6 & 150 & 6.8 & 5.8 \\
\hline $4 A$ & 8200 & 463.2 & 325 & 101.6 & 75 & 6.8 & 5.8 \\
\hline $4 B$ & 7400 & 463.2 & 325 & 101.6 & 75 & 6.8 & 5.8 \\
\hline
\end{tabular}

\subsection{Characteristics of the finite element model}

The 4-node shell element SHELL181 was used to simulate the beam's plates (web, flanges, and web stiffeners) and additional unidimensional elements (BEAM188 and LINK180) were used to prevent distortion at the supports. The steel was modeled adopting either a bilinear or a multilinear stress-strain curve, following, for each experiment simulated, the material specifications adopted by the authors responsible for the experiment. The analyses were solved using an arc-length technique (which allows the study of the post-failure behavior) combined with geometric and physical nonlinearities and large displacement 
theory. The point loads were spread along the width of the top flange and applied as a set of nodal forces. As a result of mesh refinement studies the size of the elements in each model was taken to be the smallest value given by the five following expressions: $s_{w} / 4, b_{f} / 4, d_{t} / 3, s_{d} / 8$, and $L / 100$ (in which $d_{t}$ is the height of the web above the center of the opening, and $s_{0}$ is the width of the opening).

\subsection{Calibration of the numerical model}

The experimental and numerical results extracted from the literature (compiled in Table 1 and Table 2) were compared with the numerical results obtained in the proposed numerical model. This comparison was made using three criteria to evaluate the quality of the simulation: the maximum strength of the beam, the shape of the load-displacement curve, and the failure mode (visually identified based on the deformed shape). No residual stresses were applied in this study, even though Sonck [2] and Vieira [8] did consider them in their numerical analyses. The geometric imperfections included in the proposed numerical model matched the ones adopted by the authors of each reference model in their own numerical analyses, both in shape and in magnitude. The only exceptions to this approach were the two models by Nseir et al. [4], in which a sophisticated method was developed to measure the initial geometry of the beam and transfer it to the numerical model. Since this could not be replicated, both models (HEA_340 and IPE_330) were given an initial imperfection with the shape of global bending about the weak-axis and magnitude of $L / 1000$.

The load ( $\mathrm{kN}$, vertical axis) versus displacement at mid span ( $\mathrm{mm}$, horizontal axis) curves for some of the reference models are presented in Fig. 5. The thick continuous lines represent the results obtained in the proposed numerical model, the dashed lines represent the experimental results, and the thin continuous lines represent the numerical results obtained by the authors who carried out the experimental analyses.
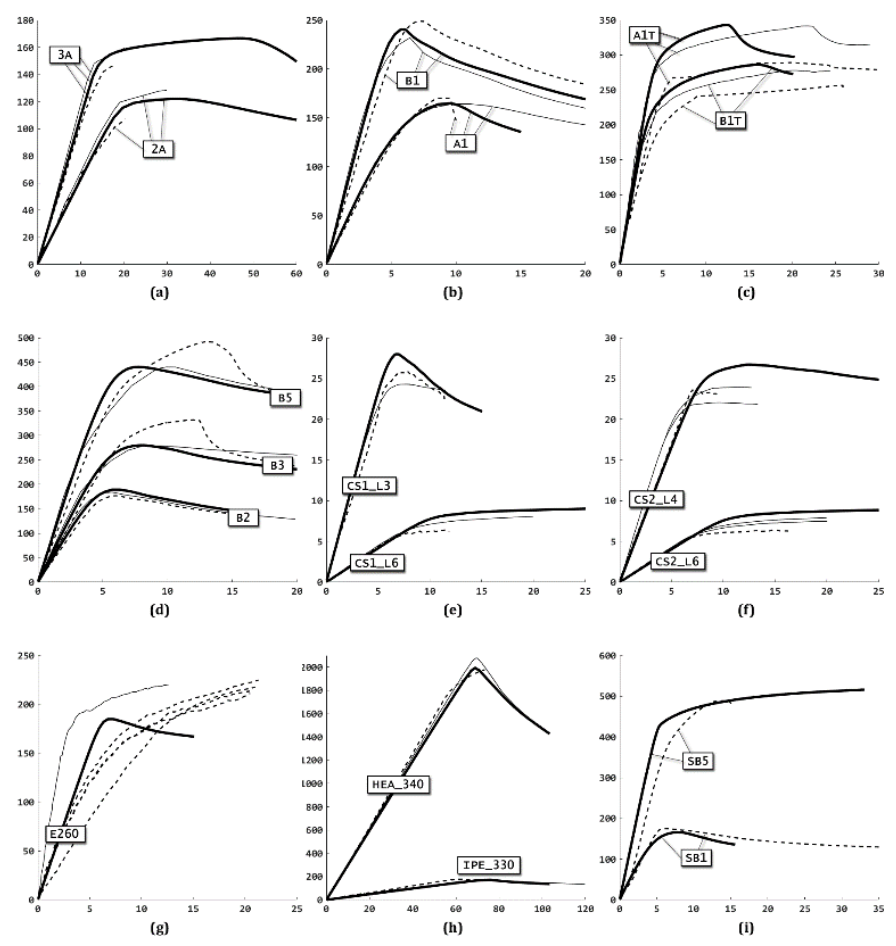

Fig. 5 Validation of the numerical model: load-displacement curves for selected beams

In general the numerical and experimental curves display good agreement. There are, however, some important differences. Model CS1_L6 (Fig. 5-e), for instance, deviated from the experimental results and predicted higher failure loads. The same tendency was observed by Sonck [2], and indeed the numerical curves (continuous lines) display matching behavior. Sonck [2] attempted to explain this discrepancy by citing difficulties with the loading equipment, which caused premature interruption of the experiment.

For model $A I T$ (Fig. 5-c) the numerical curves match each other but diverge from the experimental results in a significant manner. Tsavdaridis \& D'Mello [9] considered this result a satisfactory calibration of the numerical model. Model $B 3$ (Fig. 5-d), presented by [8], displays a similar phenomenon, with the numerical results agreeing with each other but diverging from the experimental result. Vieira [8] also considered this result satisfactory. All the numerical results corresponding to the reference models by [1] displayed very poor agreement, even though only model E260 (Fig. 5-g) is presented. Even the author's own numerical analysis failed to match the experimental results. This indicates possible problems with the experimental design or with its reporting.

The remaining models presented very good agreement between numerical and experimental results, leading to the conclusion that the proposed numerical model simulates well the behavior of castellated and cellular beams. Some of the differences between numerical and experimental results observed in this calibration might be due to inadequate assumptions made in the construction of the numerical model. One of these assumptions, namely the shape of the initial geometric imperfection, is investigated further in this paper.

\section{Study of the different shapes of geometric imperfection}

The influence of the four types of geometric imperfection presented previously (Fig. 3 and Fig. 2-b) on the behavior of castellated and cellular beams was analyzed. The numerical results obtained will always depend upon the magnitude of the geometric imperfection introduced, which, in turn, displays great variability in real world beams $[8,4]$. In an attempt to isolate the effects of the shape of the imperfection rather than that of its magnitude on the numerical model all the simulations were performed using fixed expressions for the determination of the size of the imperfection introduced. These expressions are listed in Table 3 and were chosen based on generally accepted guidelines, such as those provided by Eurocode 3 [20].

Table 3

Shapes and magnitudes of the geometric imperfections studied with the numerical model

\begin{tabular}{ccc}
\hline Shape & Code & Magnitude \\
\hline Weak-axis bending & FW & L/1000 \\
Web bending & WB & $d_{g} / 200$ \\
Buckling mode (WBS) & BM & $d_{g} / 200$ \\
Web-post misalignment & PM & Smallest between $d_{g} / 200$ and $t_{w} / 200$ \\
\hline
\end{tabular}

Due to the adoption of the fixed parametric expressions the magnitudes of the geometric imperfections no longer display any correspondence with the experimental values, used during validation. The imperfection magnitudes that were altered the most were those of the two models by Tsavdaridis \& D'Mello [9] (A1T and B1T), since the authors adopted a magnitude of $0.038 \mathrm{~mm}$ while the parametric expressions in Table 3 result in a magnitude of $2.19 \mathrm{~mm}$, a value over 50 times greater.

\subsection{Weak-axis bending $(F W)$}

The weak-axis bending, when applied to the most slender and unbraced beams, resulted in the occurrence of LTB. However, when applied to shortspanned, laterally braced beams, this same imperfection shape did not significantly affect the stability of the web-post. Fig. 6 displays loaddisplacement curves of three models simulated in ANSYS either with weak-axis bending as geometric imperfection or with no geometric imperfections.

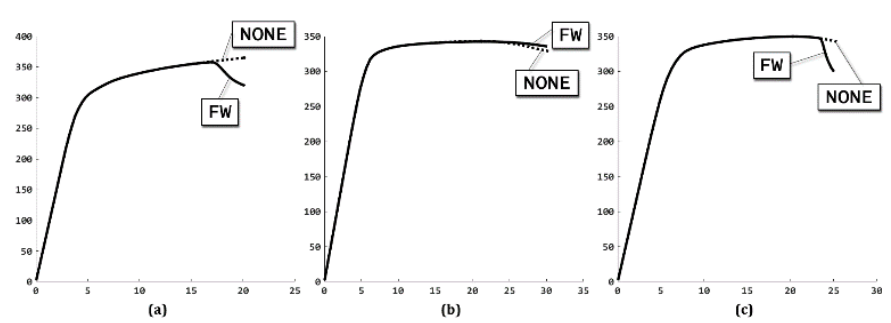

Fig. 6 A1T (a), B3 (b), and SB3 (c): global and no imperfections yielding similar results

The similarity between the pairs of curves in Fig. 6 reveals the small influence the weak-axis bending has over the behavior of short-spanned and laterally braced beams. Only after the structure has reached a high degree of plastic yielding do the two curves diverge, a behavior that has been observed in most of the beams simulated.

In some cases, however, the small influence of the global imperfection was enough to generate web-post instability. Fig. 7 displays the results of model B2, in which the occurrence of instability can be observed at the end of the linear segment of the load-displacement curve. The deformed shapes (taken at the poin of maximum load for each curve) reveal the occurrence of WBS in the model with the imperfection and the occurrence of plastic yielding (Vierendee 
mechanism and longitudinal shearing of the web-post) in the model without imperfections.

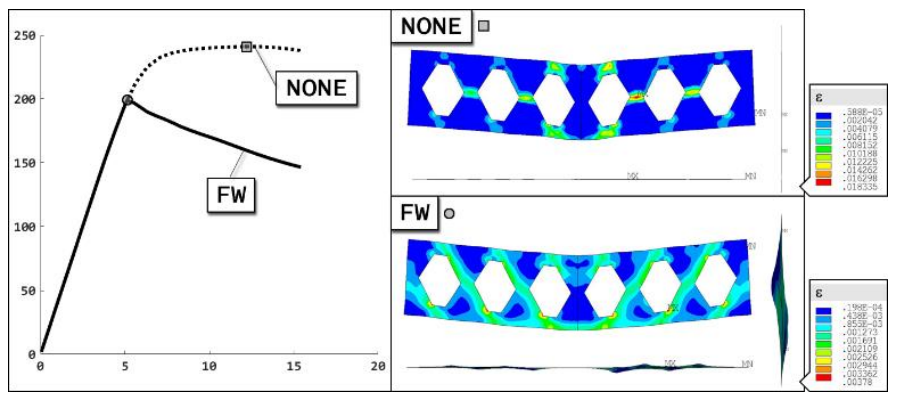

Fig. 7 Model B2: global imperfection (FW) impacting web-post stability

\subsection{Web bending $(W B)$}

The bending of the web is present in plain-webbed I-sections, but amplified by the fabrication process of cellular and castellated beams. The presence of this imperfection generates eccentricities in the centroid and shear center of the crosssection with respect to the direction of the vertical load, which leads the applied shear forces to generate torsion in the beam. In a second-order analysis of slender beams this small torsional rotation can develop into lateral-torsional buckling. For short-spanned beams the curved shape of the web-post can lead to instability, either caused by axial compression of the web-post or by diagonal compression due to shear forces.

The results obtained when web bending was introduced as geometric imperfection can be summarized as follows:

- Slender, laterally unbraced beams: collapse by lateral-torsional buckling (Fig. 8);

- $\quad$ Short-spanned beams without web stiffeners: the web-post directly under the load introduction point buckled by compression (Fig. 9);

- $\quad$ Short-spanned beams with web stiffeners: collapse happens either by WBS (Fig. 10), by longitudinal shear of the web-post (Fig. 11), or by Vierendeel mechanism (Fig. 12).

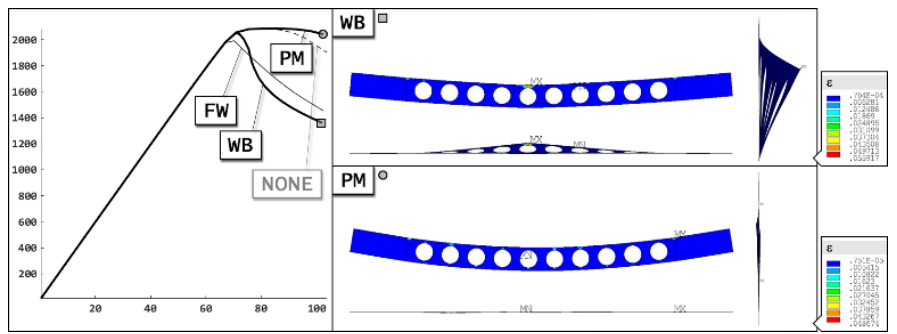

Fig. 8 Model HEA_340: collapse by either LTB or plastic yielding

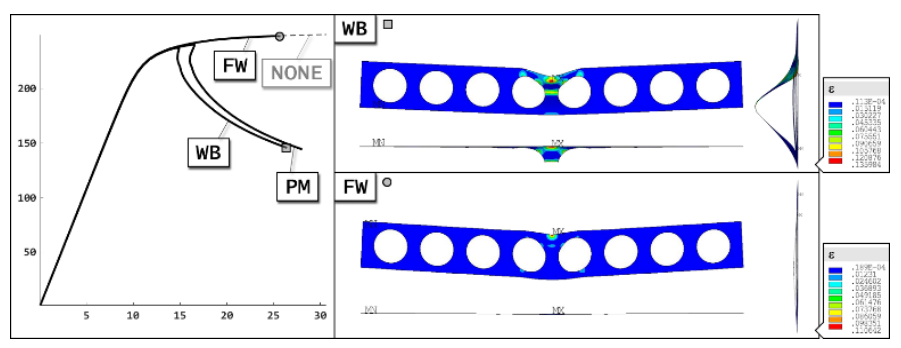

Fig. 9 Model E24OC: collapse by either WBC or plastic yielding

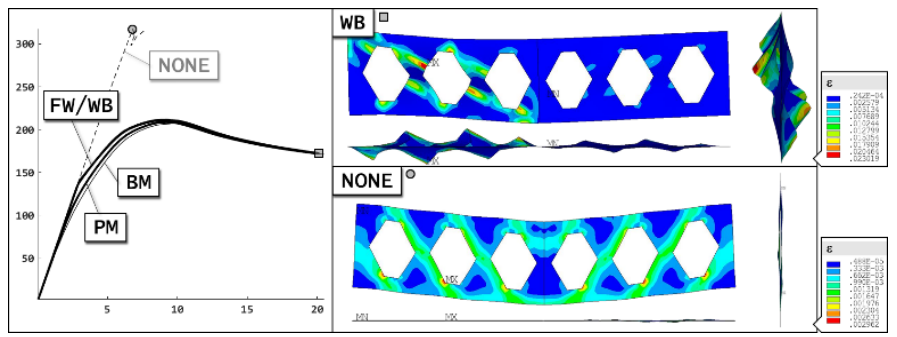

Fig. 10 Model SE1: collapse by WBS when any geometric imperfection is introduced

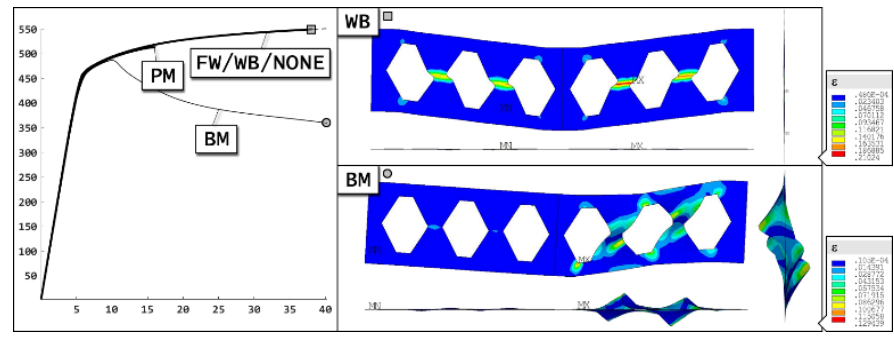

Fig. 11 Model B5: collapse by either WBS or LS

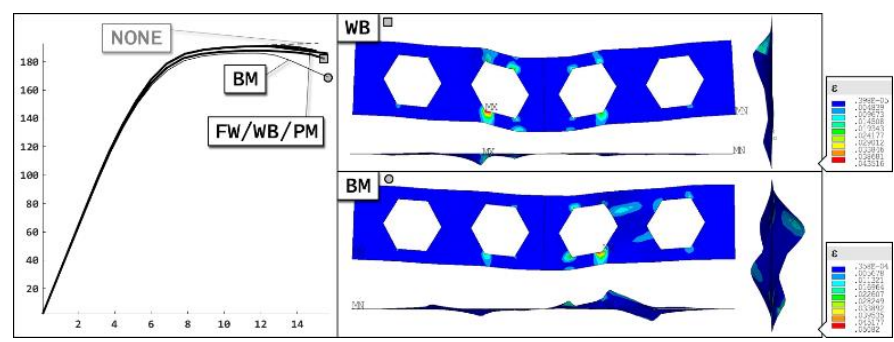

Fig. 12 Model A2: collapse by either VM or WBS

\subsection{Buckling mode shape (BM)}

The shape of the web-post buckled due to shear force was obtained in an eigenvalue analysis to then be used as geometric imperfection in the nonlinear analysis for the study of post failure behavior. This buckling mode, however, tends to occur only in short-spanned, laterally braced beams. Longer beams will display global instability, and attempts to artificially constrain the slender beam in order to facilitate the occurrence of the WBS buckling mode were unsuccessful. Therefore, the buckling mode shape was applied only to the short-spanned beams, for which the eigenvalue analysis was able to generate the desired geometric imperfection shape.

Introducing the deformed shape obtained in the eigenvalue analysis as geometric imperfection is the conventional approach, often adopted by researchers studying the problem of collapse by WBS [8.9]. In all the simulations performed the introduction of the buckling mode shape eventually led to collapse by web-post buckling due to shear (WBS), as can be seen in Fig. 11, Fig. 12, Fig 13, and Fig. 14.

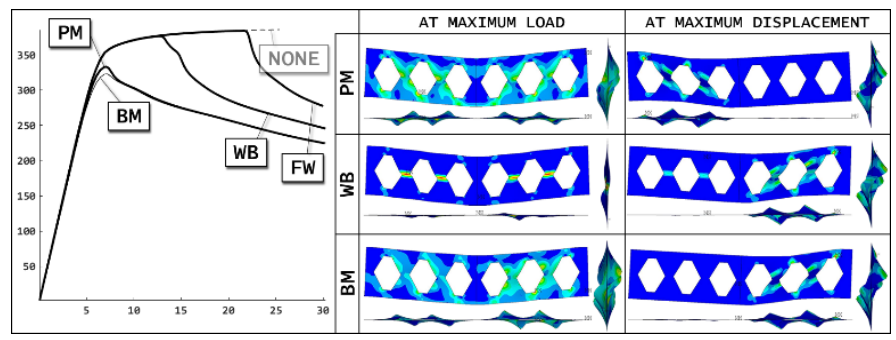

Fig. 13 Model B4: collapse by either WBS or WBS and LS

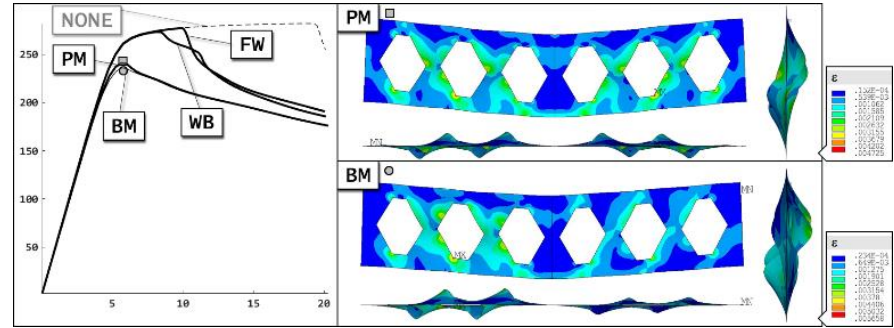

Fig. 14 Model B1: collapse by WBS

4.4. Web-post misalignment (PM)

In the standard fabrication process for castellated and cellular beams it is impossible to assure perfect alignment between the upper and lower halves of the beam during welding. To simulate this misalignment of the web in the numerical 
model the cross-sections of the shell elements in the top and bottom halves of the web were offset from the midplane in opposite directions. This approach introduces small eccentricities, but no mesh discontinuities. Due to its ease of application as a geometric imperfection the web-post misalignment was tested in all the beams studied.

The introduction of the web-post misalignment led the slender beams to collapse by global instability (LTB) in all cases except one. Model HEA_340 was this single exception, having collapsed due to the formation of a plastic hinge caused by bending moment (Fig. 8).

For short-spanned, laterally braced beams with web stiffeners the introduction of web-post misalignment led to collapse by WBS (Fig. 13, Fig. 14, and Fig. 15).

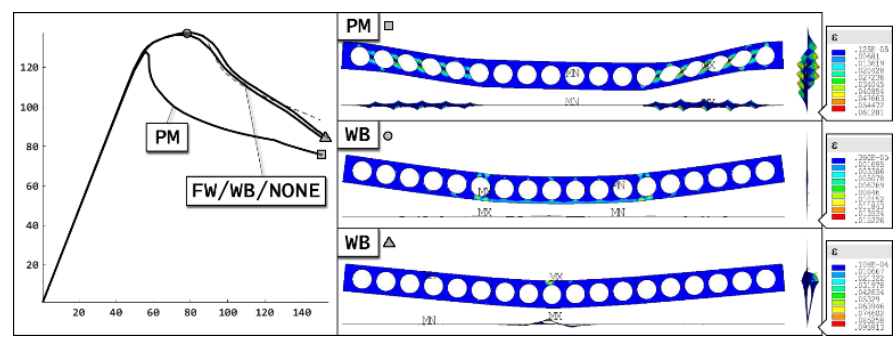

Fig. 15 Model 4B: collapse by either WBS or PH

The long-spanned but laterally braced beams (most of the beams studied by Warren [6]) collapsed due to the formation of plastic hinges caused by bending moment and shear force (Fig. 16). Short-spanned beams without web stiffeners collapsed by web-post buckling due to compression (WBC, Fig. 9).

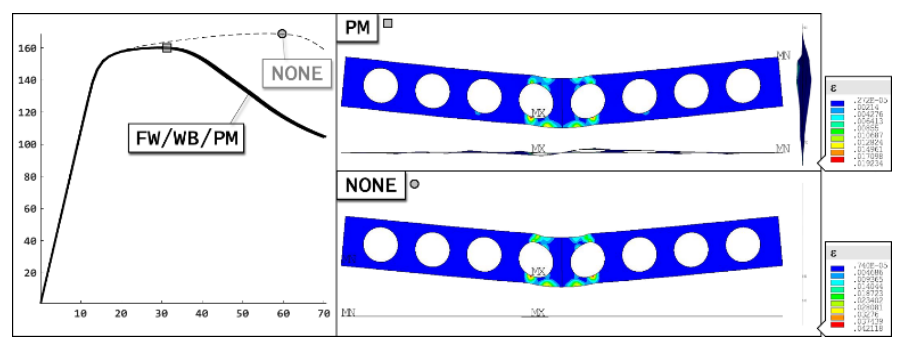

Fig. 16 Model 3A: collapse by formation of plastic hinges (PH)

\section{Discussion of the results}

The simulations performed can be roughly divided into two groups: beams that fail by global instability and beams that fail by other mechanisms. The longspanned unbraced beams $\left(C S 1 \_L 3, C S 1 \_L 4, C S 1 \_L 6, C S 2 \_L 3, C S 2 \_L 4, C S 2 \_L 6\right.$, $I P E \_330$, and $E 240 A$ ) fail by lateral-torsional buckling as long as any of the studied geometric imperfections is applied. Despite that, a comparison of the load-displacement curves indicates that different imperfection shapes lead to different ultimate resistances (Fig. 8, Fig. 17, and Fig. 18). The geometric imperfection that most reliably produces the lowest resistance against LTB is the global flexure about the weak axis of inertia. This result was expected and is in accordance with conventional approaches, that recommend the use of the first buckling mode as imperfection shape. The flexure about the weak axis does not match the LTB shape exactly for not including the torsional deformation, but it is a very close analogue.

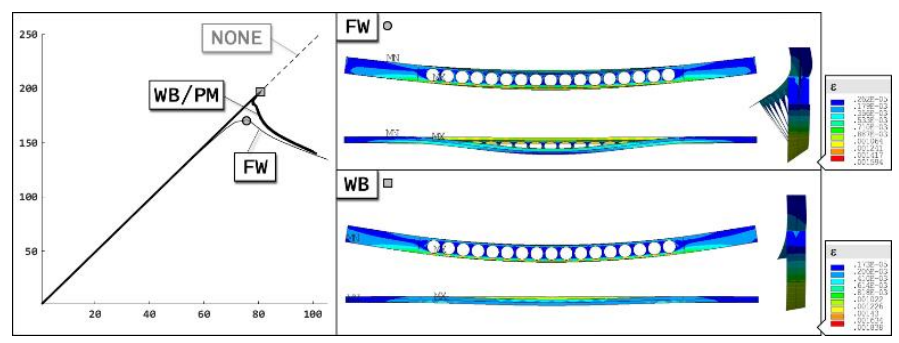

Fig. 17 Model IPE_330: collapse by LTB

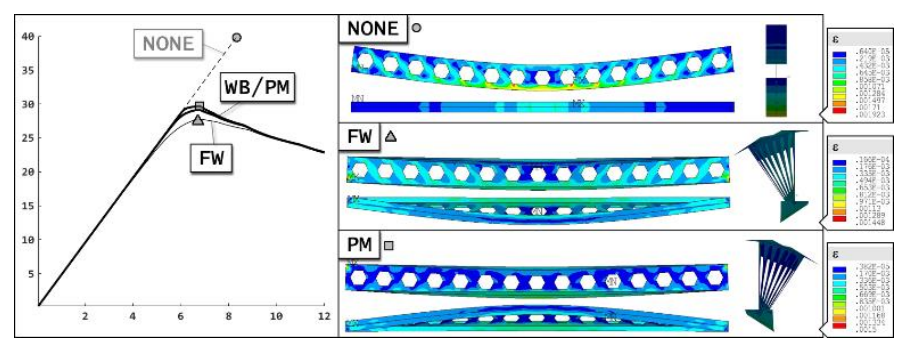

Fig. 18 Model CS1_L3: collapse by LTB when imperfections are introduced

The geometric imperfections that affect primarily the web (web-post bending and web-post misalignment) have also triggered LTB, but usually allowed the simulations to reach higher loads and led to more abrupt transitions between the linear elastic and the post-failure regimes. This abrupt transition can be observed in the load-displacement curves at the point of maximum load, especially when contrasting models with web imperfections against models with the global imperfection (Fig. 17).

In one case the introduction of the web-post misalignment was insufficient to provoke LTB and beam HEA_340 failed by plastic yielding (Fig. 8). This indicates that, at least for the magnitudes studied, the introduction of web imperfections may not be sufficient to trigger global instability in long-spanned, laterally unbraced beams. The introduction of global imperfections (first buckling mode or flexure about the weak axis of inertia) is therefore recommended.

The remaining beams simulated were laterally braced to prevent global instability. These beams displayed a great variety of failure modes, that were directly affected by the imperfections introduced. The introduction of the global imperfection (flexure about the weak-axis) caused very little effect, and many of the beams still behaved as if no geometric imperfection had been introduced. Due do its lack of impact in the models this imperfection will be excluded from further analysis.

The three remaining geometric imperfection shapes (web bending, WBS buckling mode, and web-post misalignment) produced clear and significant impacts in the structural behavior of the beams. The dominant modes of failure observed in the numerical model were web-post buckling due to shear (WBS), web-post buckling due to compression (WBC), Vierendeel mechanism (VM), longitudinal shear at the web-post (LS), and plastic hinges due to bending ( $\mathrm{PH})$. Each of these modes has clear definitions in the literature [5,6,10], but they do not always occur in isolation. These failure modes can be grouped into two categories: collapse by instability (WBS, WBC) and collapse by plastic yielding (VM, LS, PH).

To better comprehend the types of collapse that occurred in the numerical model both the deformed shape and the first principal strain pattern were carefully inspected. This was necessary because beams that displayed very similar deformed shapes, often those characteristic of collapse by instability, could also have strain patterns that pointed to different modes of collapse by plastic yielding. The first principal strain was found to be the quantity best suited to tease out plastic yielding in beams dominated by web-post instability. As a result of this approach the beams that displayed web-post buckling due to shear were further divided into three groups:

- $\quad$ pure WBS: no signs of any mode of failure except web-post buckling due to shear (Fig. 10, Fig. 13, Fig. 14, and Fig. 15);

- WBS+LS: simultaneous presence of WBS and longitudinal shear at the web post (Fig. 13);

- WBS+VM: simultaneous presence of WBS and Vierendeel mechanism (Fig. 12).

The different types of collapse (instability and plastic yielding) are also reflected in the shape of the load-displacement curve. Fig. 19 presents three loaddisplacement curves, each characteristic of one type of collapse. Type A curve is associated with collapse by instability. At the end of the linear-elastic segment the model experiences a short curved segment, at the end of which the maximum load is reached. After this point the displacements grow quickly and the load decreases. Type $B$ curve is associated with collapse by plastic yielding. The linear-elastic segment is followed by a short curved segment that leads into a new linear segment, less steep than the first one and sometimes approaching a plateau. Development of plastic yielding occurs in the second linear segment. The displacements grow quickly while the load grows at a much slower rate. The curve ends at the point of maximum load, when the finite element model can no longer find stable configurations for the beam. Type $C$ curve combines the two phenomena, with instability following plastic yielding. At first the beam suffers some sort of plastic yielding as indicated by the second ascending linear segment, but this regime is ended by the occurrence of instability, characterized by the sudden decrease in applied load. 


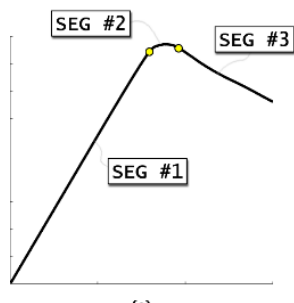

(a)

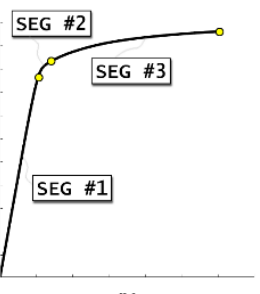

(b)

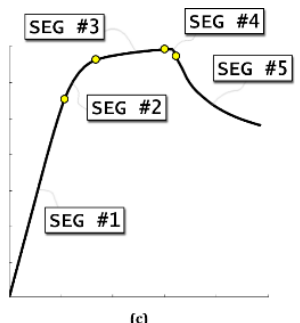

(c)
Fig. 19 Shapes of load-displacement curves associated with different types of collapse

Given the types of collapse described above the effect of each geometric imperfection can be analyzed. Table 4 summarizes the results of the numerical analyses performed. For beams that fail by web-post buckling due to shear (WBS) the results indicate that the collapse is more likely to be accompanied by some sort of plastic yielding when web bending is introduced as geometric imperfection. When either web-post misalignment or the first buckling mode are introduced the beams are pushed towards experiencing pure WBS.

Table 4

Types of collapse depending upon the shape of gometric imperfection introduced

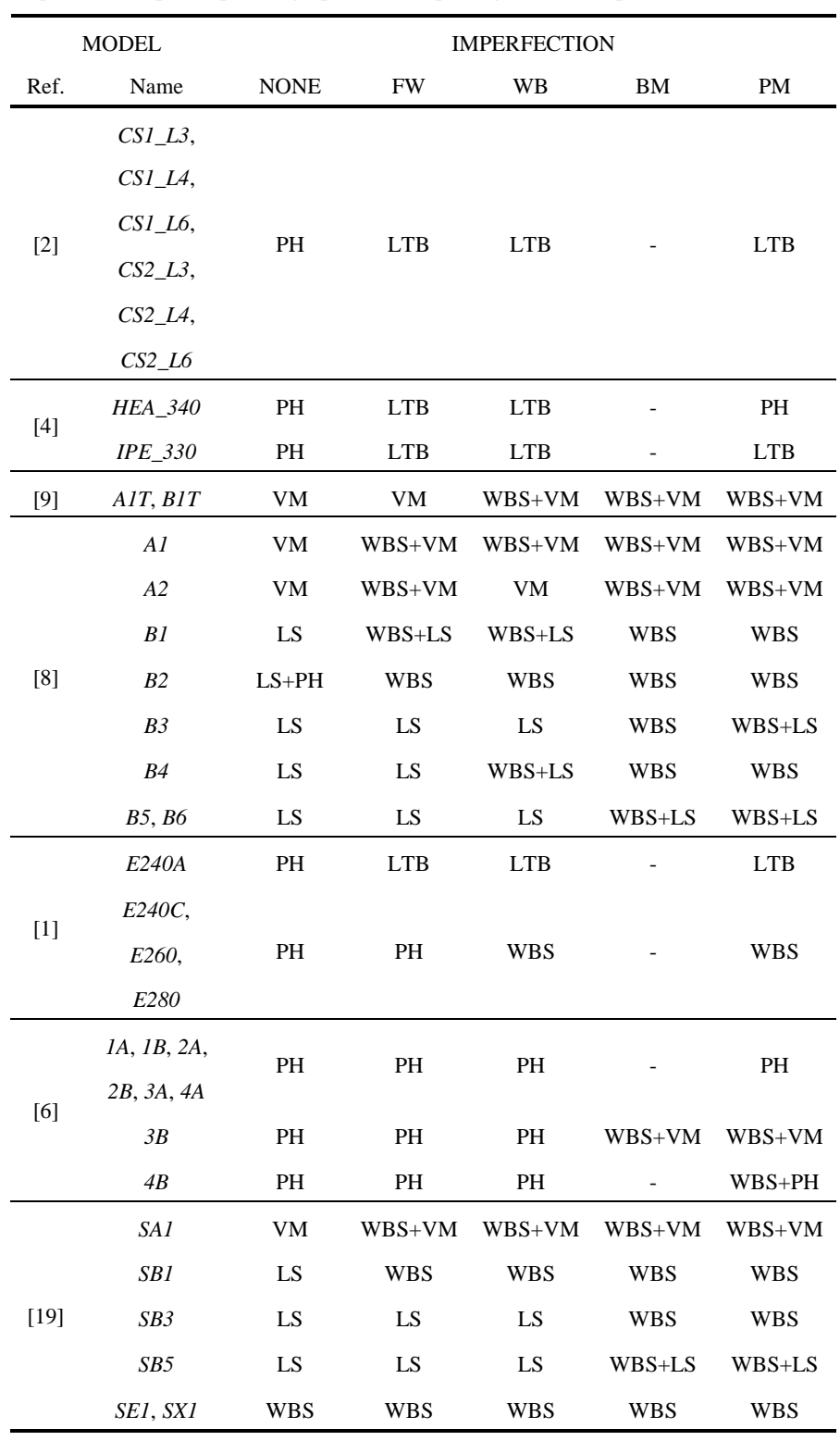

Models $B 4$ (Fig. 13) and SB3 (Fig. 20) provide the clearest examples of the effect of different shapes of geometric imperfection. The shape of the loaddisplacement curves indicates that beams with either web-post misalignment or first buckling mode as geometric imperfection failed by web-post instability. Inspection of the first principal strain patterns (highest values form narrow diagonal bands) confirms pure WBS. The beams with web bending, on the other hand, display load-displacement curves that indicate the occurrence of plastic yielding followed then by web-post instability. Inspection of the first principal strain patterns corroborates this conclusion and also reveals that both beams display a pattern characteristic of longitudinal shear at the web-post (maximum strain values form horizontal bands at the center of the web-post).

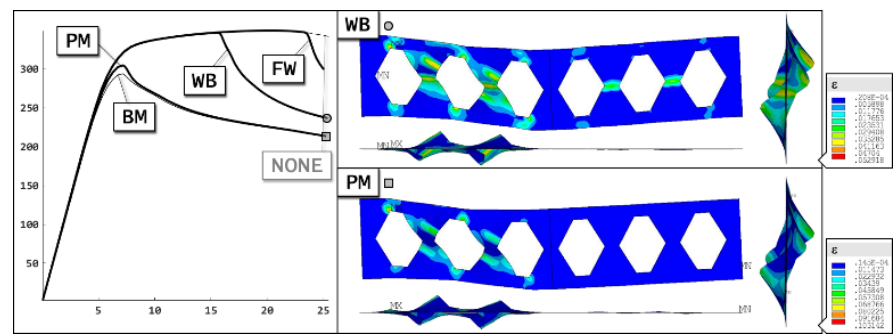

Fig. 20 Model SB3: collapse by WBS, sometimes accompanied by LS

As the study of models $B 4$ and SB3 shows, the choice of geometric imperfection shape significantly affects the results of the simulation, both qualitatively (changing the failure modes) and quantitatively (web bending led to higher overall resistance). While the adoption of the first buckling mode as a geometric imperfection might be justified on grounds of erring on the side of caution, a comparison with experimental results indicates that this approach might lead to overly conservative resistance values or even to an incorrect prediction of the failure mode for castellated and cellular beams. Fig. 21 presents a case in which the use of WBS buckling mode as geometric imperfection (BM) leads to a disparity of this nature between numerical simulation and experimental results, with the numerical simulation predicting collapse by WBS while the experimental curve indicates development of plastic yielding before instability occurs.

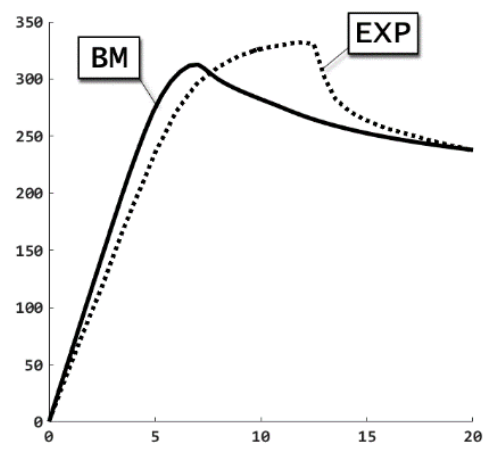

Fig. 21 Model B3: mismatch between numerical simulation and experimental result

\section{Conclusions}

Simulating the structural behavior of castellated and cellular beams using finite element models requires an accurate understanding of the influence of real world deviations in geometry. This paper studied, using a properly calibrated numerical model, the effects of four different types of geometric imperfection: weak-axis bending (FW), web bending (WB), WBS buckling mode (BM), and web-post misalignment (PM). The magnitudes of the imperfections were fixed at $L / 1000$ for the global imperfection (FW) and at $d_{g} / 200$ for the local imperfections. The conventional approach (introducing the shape obtained in an eigenvalue buckling analysis as geometric imperfection) was contrasted with the novel approach of introducing imperfection shapes that more closely resemble experimental measurements.

The global imperfection was found to have an effect only in long-spanned, laterally unbraced beams, in which it triggered collapse by lateral-torsional buckling. Short-spanned, laterally braced beams were mostly unaffected by weak-axis bending. The local imperfections (WB, BM, and PM) also led to LTB when applied to slender beams. In general, however, the introduction of the global imperfection more reliably led to LTB and to lower overall resistances, and therefore the conventional approach is recommended for slender beams.

It is important to note that the WBS buckling mode (BM) could not be applied to most slender beams. This was due to the fact that its introduction requires that it first be obtained in an eigenvalue analysis, which could not be done in most cases. This limitation, characteristic of the conventional approach, means the engineer has little control over the shape of the geometric imperfection 
introduced.

For laterally braced beams the introduction of web-based imperfections (WB $\mathrm{BM}$, and PM) led to a great variety of modes of failure, with results heavily dependent upon the geometry of the beams. Short-spanned, laterally braced beams manifested most clearly the influence of the shape of geometric imperfection. In these beams the lack of imperfection led to collapse by plastic yielding (longitudinal shear at the web-post or Vierendeel mechanism), but the introduction of web-based imperfections affected the stability of the web-post.

The web bending (WB) had the weakest effect on web-post stability. Its introduction usually led to collapse that was either entirely plastic (LS or VM) or a form of WBS heavily tainted with plastic yielding (WBS+LS or WBS+VM). The development of plastic yielding followed by web-post buckling due to shear (WBS) can be detected in the shape of the load-displacement curve (Fig. 19) and in the patterns formed by the first principal strain (Fig. 20).

The web-post misalignment (PM) and the WBS buckling mode (BM) produced very similar effects on short-spanned, laterally braced beams. Both imperfections strongly affected the web-post stability, with the buckling mode compromising it the most. In most cases the difference between PM and BM was hard to detect, but in a few beams (Fig. 11 and Fig. 12) the introduction of the web-post misalignment allowed greater development of plastic yielding before triggering collapse by WBS.

The web-post misalignment and the buckling mode (WBS-shape) can, the results suggest, be adopted interchangeably. This means that the structural behavior changes triggered by the WBS-shape, that were once restricted to geometries for which this imperfection could be obtained in an eigenvalue analysis, can now be included in any castellated or cellular beam through the introduction of the web-post misalignment, an imperfection that can be easily and universally applied.

\section{Acknowledgments}

The authors wish to thank CPNq, CAPES, and FAPEMIG for the financial support provided for the development of this research study.

\section{References}

[1] F. Erdal, Ultimate load capacity of optimally designed cellular beams, Ph.D. thesis, Middle East Technical University (2011)

[2] D. Sonck, Global buckling of castellated and cellular steel beams and columns, Ph.D. thesis Ghent University (2014)

[3] N. Boissonnade, J. Nseir, M. Lo, H. Somja, Design of cellular beams against lateral torsional buckling, Proceedings of the Institution of Civil Engineers - Structures and Buildings 167 (2014) 436444. doi:10.1680/stbu.12.00049.

[4] J. Nseir, M. Lo, D. Sonck, H. Somja, O. Vassart, N. Boissonnade, Lateral torsional buckling of cellular steel beams, Proceedings of the Annual Stability Conference - Structural Stability Research Council (2012)

[5] R. M. Lawson, S. J. Hicks, Design of Composite Beams with Large Web Openings, SCI, 2011

[6] J. Warren, Ultimate load and deection behaviour of cellular beams, Master's thesis, School of Civil Engineering, Surveying and Construction - University of Natal (2001).

[7] K. Chung, T. Liu, A. Ko, Investigation on vierendeel mechanism in steel beams with circular web openings, Journal of Constructional Steel Research 57 (5) (2001) 467490 doi:https://doi.org/10.1016/S0143-974X(00) 00035-3.

[8] W. B. Vieira, Estudo numérico-experimental da ambagem do montante de alma em vigas casteladas de aço, Ph.D. thesis, Universidade Federal de Viçosa (2015)

[9] K. D. Tsavdaridis, C. D'Mello, Web buckling study of the behaviour and strength of perforated steel beams with dierent novel web opening shapes, Journal of Constructional Steel Research 67 (10) (2011) 1605 1620. doi: https://doi.org/10.1016/j.jcsr.2011.04.004.

[10] D. Kerdal, D. Nethercot, Failure modes for castellated beams, Journal of Constructional Steel Research 4 (4) (1984) 295 - 315. doi:https://doi.org/10.1016/0143-974X(84)90004-X.

[11] Guo J., Research on distribution and magnitude of initial geometrical imperfection affecting stability of suspen-dome, Advanced Steel Construction Vol. 7, No. 4, pp. 344-358 (2011).

[12] Zhao Z. W., Liu H. Q., Liang B., Yan R. Z., Influence of random geometrical imperfection on the stability of single-layer reticulated domes with semi-rigid connection, Advanced Steel Construction Vol. 15, No. 1 (2019) 93-99. DOI: 10.18057/IJASC.2019.15.1.12.

[13] Masri O. Y. E., Lui E. M., Influence of imperfections on the flexural resistance of steel delta girders, Advanced Steel Construction Vol. 15, No. 2 (2019) 157-164. DOI: 10.18057/IJASC.2019.15.2.5.

[14] E. Ellobody, Nonlinear analysis of cellular steel beams under combined buckling modes, ThinWalled Structures 52 (2012) 66 - 79. doi: https://doi.org/10.1016/j.tws.2011.12.009.

[15] E. Ellobody, Interaction of buckling modes in castellated steel beams, Journal of Constructiona Steel Research 67 (2011) 814 - 825. doi: https://doi.org/10.1016/j.jcsr.2010.12.012.

[16] Gehring A., Saal H., Numerical analyses of cold-formed thin-walled sections with consideration of imperfections due to the production process, Advanced Steel Construction Vol. 5, No. 2, pp. 151-163 (2009).

[17] ArcelorMittal, Angelina beams - A new generation of castellated beams (2016).

[18] I. ANSYS, ANSYS Mechanical APDL, Release 14.0 - Help System (2011).

[19] G. S. Veríssimo, E. K. H. Sakiyama, J. L. R. Paes, J. C. L. Ribeiro, R. H. Fakury, R. B. Caldas, W. B. Vieira, Estudo numérico-experimental do desempenho estrutural de vigas alveolares soldadas, Tech. rep., Universidade Federal de Viçosa (2017).

[20] EN, EN 1993-1-5 Eurocode 3: Design of steel structures - Part 1-5: General rules - Plated structural elements, CEN, Brussels, 2006. 